\title{
CAD MODELLING OF PARALLEL ROBOT (TRIPOD) IN MATLAB/SIMULINK
}

\author{
Maja Anačkova, Hristijan Mickoski \\ Faculty of Mechanical Engineering, "Ss. Cyril and Methodius" University in Skopje, \\ Karpoš II bb, P.O. box 464, 1001 Skopje, Republic of North Macedonia \\ maja.anachkova@mf.edu.mk
}

\begin{abstract}
A b s t r a c t: The purpose of this paper is to create a model simulation of a parallel robot with PID controller using the programming package Matlab/ Simulink. In this paper, forward and inverse kinematics of parallel robot tripod is presented; model of the parallel robot in the programming package Solid Works is constructed; simulation model of the parallel robot tripod is made by conversion from Solid Works to Matlab/Simulink and results for velocities and accelerations in its kinematic joints are obtained that serve to the management and control of the mobile platform as a major problem in the construction of a parallel robot. Model simulation of parallel robot will be the basis for creating models of parallel robots with more complex structure, detailed understanding of their kinematics and control design as an inevitable part of the future of robotics and mechatronic.
\end{abstract}

Key words: parallel robots; tripod; parallel robot kinematics; model simulation

\section{САD-МОДЕЛИРАЊЕ НА ПАРАЛЕЛЕН РОБОТ (ТРИПОД) ВО МАТLАВ/SIMULINК}

А п с т р а к т: Целта на овој труд е креирање на имитационен модел на паралелен робот со пропорционално целосно деривирано (PID) управување во програмскиот пакет Matlab/ Simulink. Bо овој труд е разработена директна и инверзна кинематика на паралелен робот со три нозе; модел на паралелниот робот е изработен во софтверскиот пакет Solid Works; имитационен модел на паралелен робот со три нозе е добиен со префрлање на моделот од Solid Works во програмскиот пакет Матлаб/Симулинк и се добиени резултати за брзините и забрзувањата во неговите кинематски врски кои служат за управување и контрола на движењето на подвижната платформа, што е главна задача при конструкција на еден паралелен робот. Симулацијата на модел па паралелен робот со три нозе ќе биде основа за креирање на модели на паралелни роботи со многу посложена структура, детално разбирање на нивната кинематика и управување како неизбежен дел од иднината на роботиката и мехатрониката.

Клучни зборови: паралелен робот; кинематика на паралелен робот; симулација на модел

\section{INTRODUCTION}

In the last decades, parallel robots have motivated a great interest because of their characteristics of small moving masses, preciseness and highspeed controllability compared to the serial robots. They have been widely used for the reconfigurable structure due to their inherent modularity. Such design and analysis for a reconfigurable parallel robot is given in [1] and [2]. Generally, parallel robots are constructed from a fixed, called stationary platform, a mobile or moving platform and legs which connect these two platforms. This parallel kinematics have significant advantages over the serial robots because of their accuracy, rigidness and higher load capacity. These parallel kinematics machines (PKMs) have many applications such as from aircrafts simulators, machining tools, micro-motion machines [3]. In industrial applications, most widely used are the parallel robots that generate spherical rotation around a certain point as shown in [4].

The problem of kinematics of these parallel structures means determination of their direct and inverse kinematics equations. The direct kinematics explains the motion in terms of a base fixed 
Cartesian coordinate systems according to which the position and orientation of the end effector (in this case the moving platform) are determined. The inverse kinematics is more complex, it includes calculation of the possible values for the angular and linear displacements of the joints in order for the mobile platform to achieve a certain trajectory or a desired position [5]. A comparative analysis of these two methods is presented in [6].

The kinematics and dynamics problems of the robots in general are solved by using the modelling and simulation methods in a certain software that supports this analysis. Most commonly used software is Matlab software package, more concisely Matlab/Simulink which allows this kind of identification and analysis of the robot parameters in a virtual environment. It allows real-time simulations of the motion of the robot showing the changes in the position, velocity and acceleration of a desired joint or body [7]. From the simulated model of parallel manipulator in [8] it can be concluded that the choice of the generalized coordinate does not provide a unique determined position on the mobile platform without taking into account the conditions of the kinematic joints, linear and the angular velocities. Matlab/Simlunk also allows integrating a control algorithm and the response of the robot under the given control. A model of 3-RRR planar parallel robot controlled by a PID controller in Matlab/Simulink is explained in [9].

In this paper, a three-legged RRR parallel robot model in the Solid Works program packagewas developed as given in Section 2. Based on this model, a simulation of the movement of the movable platform (its trajectory) was later conducted considering the direct and inverse kinematics explained in Section 3. Further, PID control was implemented and graphs of the dynamic parameters were exported and shown in Section 4 in order to understand the motion of the movable platform.

\section{MODELLING OF THE TRIPOD IN SOLID WORKS}

The kinematic and dynamic analytical study of different systems (mechanical, electrical, etc.) is usually done by their modelling and simulation. The goal of the modelling process of a single system is to create an adequate, verifying model of the system. Thus, all the necessary research and system studies can be performed on the model instead of a real system, which saves time and resources.
Modelling is the most important stage in the research of a single system. It should lead to a model that will contain the basic properties of the system necessary to solve the tasks of the research. The model should be fully available for the means of appropriate science and mathematics and to store all the characteristic elements of the systems output. Closely related to the modelling process is the process of simulation. The term simulation refers to an experimental approach for analyzing and observing the functional properties of a system using its simplified model. The simulation of mechanical systems gives us visualization of the dynamic behaviour of the mechanical system. At the core of the simulation is the verifying model of the system as a real object for testing. Simulation is not a method to make an optimal solution, but provides an opportunity to evaluate the quality of the system relative to another. It represents an experiment performed on the model. In order to understand and analyze the properties of parallel robots, a three-legged parallel robot model was designed in the Solid Works program package.

The model of parallel robot consists of a stationary (bottom) platform, three legs representing clips that can perform a translatory movement and a movable (upper) platform (Figure 1). The bottom platform fixed to the base through the three pairs of screws and nuts. The joints of the platform's legs are made by means of rotational connections (Figure 2).

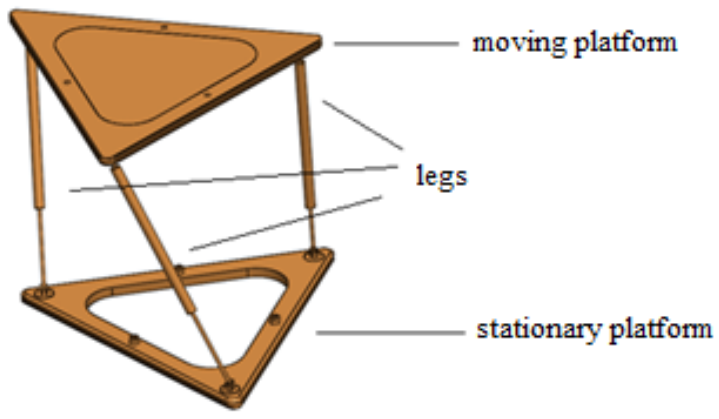

Fig. 1. Model of tripod in "Solid Works"

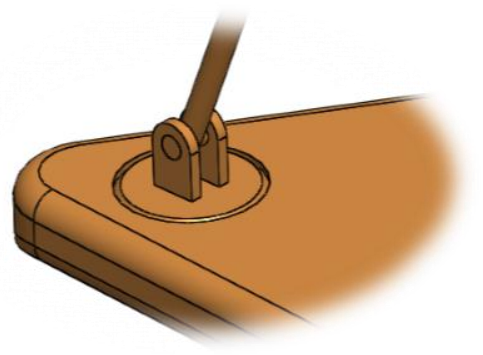

Fig. 2. Rotational joints between the legs and the stationary platform 
The lower and upper platforms are flat triangles that are identical by their dimensions (Figure 3).

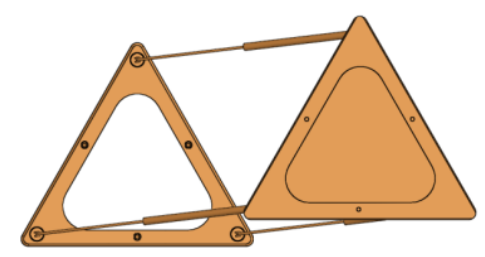

Fig. 3. Platform geometry

Tripod motion is allowed in three degrees of freedom: translation along the $y$-axis (top-down) (Figure 4a), rotation around the $y$-axis (Figure 4b) and translation by $z$-axis (Figure $4 c$ ).
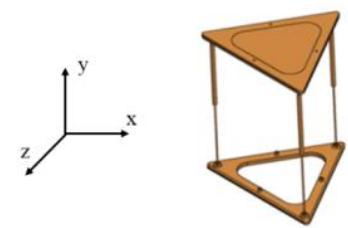

a)

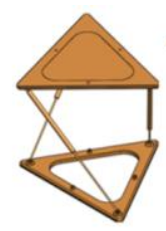

b)

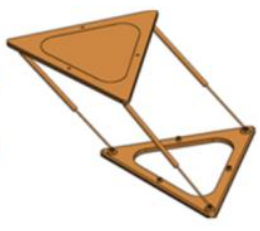

c)
Fig. 4. Degrees of freedom of the tripod

Since we have already defined the geometry and degrees of freedom of this robot, we can easily obtain the equations for its direct and inverse kinematics.

\subsection{Direct kinematics}

The rotational connections attached to the fixed platform are $A_{i}$, while those on the mobile platform are $B_{i}$, where $i=1,2,3$. Accordingly, the three feet of the robot will be $A_{i} B_{i}$. The points $A_{i}$ and $B_{i}$ form a flat triangle with sides $a$ and $b$ respectively. We specify the lengths of the sides with $i=1,2,3$ and their slope to the fixed base is 0 , i.e. they are placed at right angles to the base (Figure 5).

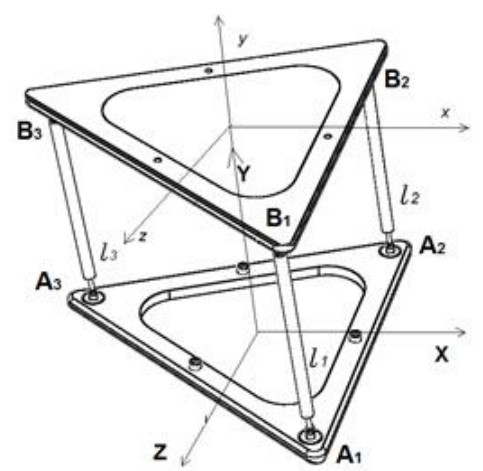

Fig. 5. Coordinate systems of the platforms
On the stationary platform, we join the coordinate system $A_{x y z}$, such that point $A$ is at the center of the symmetry of the base, the axes $x$ and $z$ lie on the base, and the $y$-axis is normal to the stationary platform. Analogously, the $B_{x y z}$ coordinate system is attached on the mobile platform. The positions of the rotational pairs $A_{1}, A_{2}, A_{3}$ in the $A_{x y z}$ coordinate system are:

$$
\begin{aligned}
& A_{1}=\left(\frac{a}{2}, 0, \frac{a}{2}\right)^{T}=\left(A_{11}, A_{12}, A_{13},\right)^{T}, \\
& A_{2}=\left(\frac{a}{2}, 0,-\frac{a}{2}\right)^{T}=\left(A_{21}, A_{22}, A_{23},\right)^{T}, \\
& A_{3}=(-R, 0,0)^{T}=\left(A_{31}, A_{32}, A_{33},\right)^{T} .
\end{aligned}
$$

Similarly, the positions of the rotational pairs with respect to the $B_{x y z}$ coordinate system are:

$$
\begin{aligned}
& B_{1}=\left(\frac{b}{2}, 0, \frac{b}{2}\right)^{T}=\left(B_{11}, B_{12}, B_{13},\right)^{T}, \\
& B_{2}=\left(\frac{b}{2}, 0,-\frac{b}{2}\right)^{T}=\left(B_{21}, B_{22}, B_{23}\right)^{T},
\end{aligned}
$$

$$
B_{3}=(-r, 0,0)^{T}=\left(B_{31}, B_{32}, B_{33},\right)^{T} .
$$

The position of the mobile platform relative to the stationary platform is determined by the Euler angles $\varphi_{1}$ and $\varphi_{2}$ and the vector $B=\left(0, B^{T}\right)$. The geometric relationship of the coordinate systems, that is, the position of the movable coordinate system relative to the stationary of the lower platform is described using a $4 \times 4$ matrix with homogeneous transformations:

$$
\begin{aligned}
T & =T\left(0, \varphi_{1}, \varphi_{2}\right)= \\
& =\left[\begin{array}{cccc}
\cos \varphi_{1} & -\dot{\sin } \varphi_{1} & 0 & 0 \\
\sin \varphi_{1} \cos \varphi_{2} & -\cos \varphi_{1} \cos \varphi_{2} \sin \varphi_{2} & 0 \\
\sin \varphi_{1} \sin \varphi_{2} & -\cos \varphi_{1} \sin \varphi_{2} \cos \varphi_{2} & 0 \\
0 & 0 & 0 & 1
\end{array}\right]
\end{aligned}
$$

From the previous equation follows that the position of the rotational pairs $B_{i}$ in relation to the coordinate system $A_{x y z}$ are determined by the vector:

$$
\begin{aligned}
{\left[B_{i}\right] } & =\left(\begin{array}{c}
{\left[B_{i, 1}\right]} \\
{\left[B_{i, 2}\right]} \\
{\left[B_{i, 3}\right]} \\
1
\end{array}\right)=T\left(0, \varphi_{1}, \varphi_{2}\right)\left(\begin{array}{c}
{\left[B_{i, 1}\right]} \\
{\left[B_{i, 2}\right]} \\
{\left[B_{i, 3}\right]} \\
1
\end{array}\right)= \\
& =T\left(0, \varphi_{1}, \varphi_{2}\right) B_{i}=T B,
\end{aligned}
$$




$$
\begin{aligned}
& {\left[B_{1}\right]=\left(\begin{array}{c}
\frac{b}{2} \cos \varphi_{1} \\
\cdot \frac{b}{2} \sin \varphi_{1} \cos \varphi_{2}+\frac{b}{2} \sin \varphi_{2} \\
\cdot \cdot \frac{b}{2} \sin \varphi_{1} \sin \varphi_{2}+\frac{b}{2} \cos \varphi_{2} \\
1
\end{array}\right),} \\
& {\left[B_{2}\right]=\left(\begin{array}{c}
\frac{b}{2} \cos \varphi_{1} \\
\cdot \cdot \cos \varphi_{2}-\frac{b}{2} \sin \varphi_{2} \\
\cdot \sin \varphi_{1} \cos \varphi_{2}+\frac{b}{2} \cos \varphi_{2} \\
\frac{b}{2} \sin \varphi_{1} \sin \varphi_{2}
\end{array}\right)} \\
& {\left[B_{3}\right]=\left(\begin{array}{c}
-r \cos \varphi_{1} \\
-r \sin \varphi_{1} \cos \varphi_{2} \\
-r \sin \varphi_{1} \sin \varphi_{2} \\
1
\end{array}\right) \text {. }}
\end{aligned}
$$

Consequently, the generalized coordinate $l_{i}$ is calculated according to the following equation:

$l_{i}=l_{i}\left(0, \varphi_{1}, \varphi_{2}\right)=\sqrt{\sum\left(A_{i, j}-\left[B_{i, j}\right]\right)^{2}}$,

$j=1,2,3$ and $i=1,2,3$.

\subsection{Inverse kinematics}

The rotational pairs are designed on the base (stationary platform) with $A, B$ and $\mathrm{C}$ while they are on the movable platform with $a, b$, and $c$. We represent the lengths of the legs with the generalized $l_{1}, l_{2}$ and $l_{3}$ coordinates:

$$
\begin{aligned}
l_{1} & =\left(X_{A_{1}}-X_{B_{1}}\right)^{2}+\left(Y_{A_{1}}-Y_{B_{1}}\right)^{2}+ \\
& +\left(Z_{A_{1}}-Z_{B_{1}}\right)^{2}, \\
l_{2} & =\left(X_{A_{2}}-X_{B_{2}}\right)^{2}+\left(Y_{A_{2}}-Y_{B_{2}}\right)^{2}+ \\
& +\left(Z_{A_{2}}-Z_{B_{2}}\right)^{2}, \\
l_{3} & =\left(X_{A_{3}}-X_{B_{3}}\right)^{2}+\left(Y_{A_{3}}-Y_{B_{3}}\right)^{2}+ \\
& +\left(Z_{A_{3}}-Z_{B_{3}}\right)^{2} .
\end{aligned}
$$

\section{MODEL SIMULATION IN MATLAB/SIMULINK}

For faster and more efficient problem solving in the modern practice, advanced software and software packages are required. Such program package is Matlab created from MathWorks and it is a programming language for technical calculations which can also perform visualization and programming. The Simulink programming package is a part of Matlab software and has a great application in the modelling, simulation and analysis of dynamic systems in multiple areas. It is practical, because it can work with non-linear and linear systems, and can work in discrete and continuous time. It also can explore real models, their impact from friction, air resistance, etc., which are real phenomena and affect the real model. Simulink uses a block library that, with a simple drag-and-drop procedure, ships into a separate window for a model and with appropriate arranging of the blocks, a model that can be easily repaired and updated is created. It is connected to the Matlab tools and has instant access to them, therefore Simulink models can be easily analyzed and visualized (Figure 6).

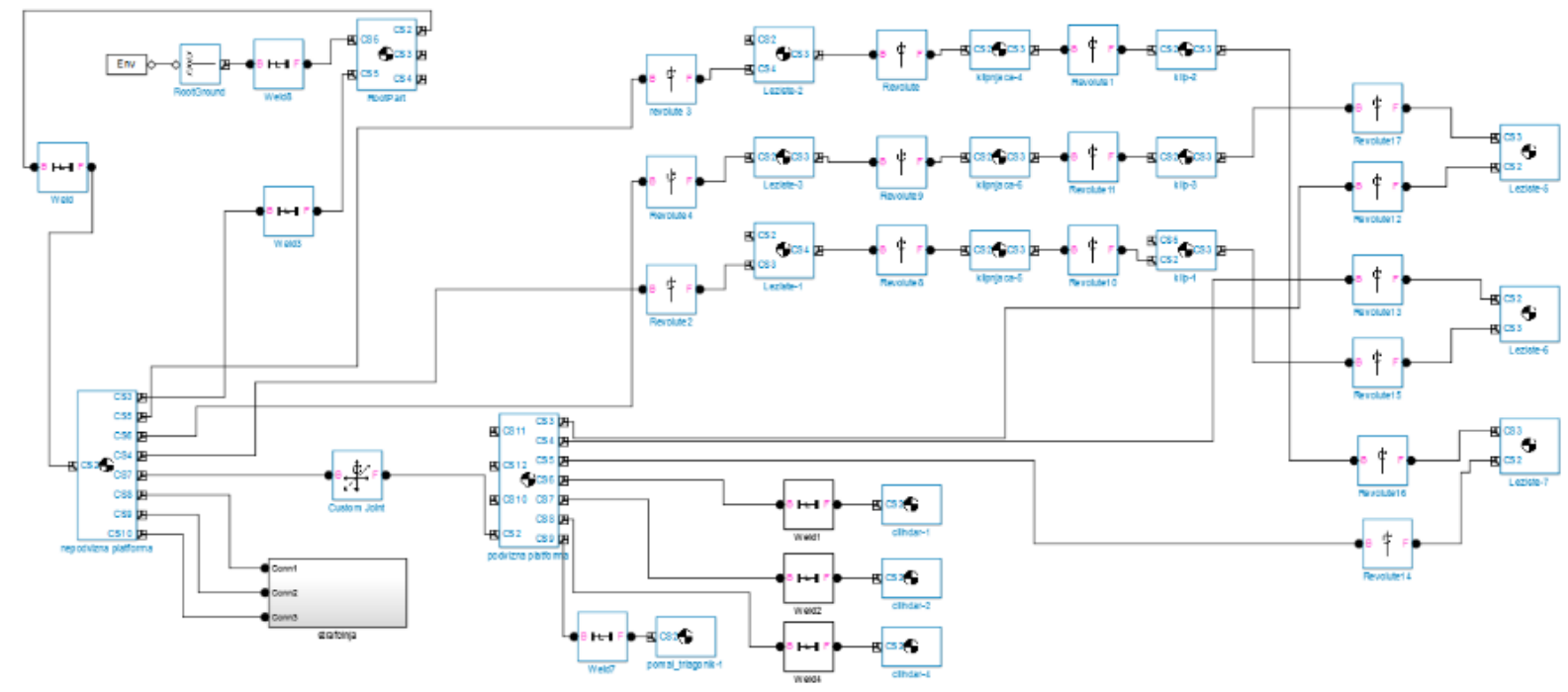

Fig. 6. Block scheme of the tripod in Simulink 
Once the Solid Works model is developed, in order to perform a simulation it should be transferred to Matlab/Simulink which is enabled automatically by the Multibody tool provided by MathWorks.

The first generation of SimMechanics under Matlab/Simulink includes a library of blocks and visualization tools that have been released in SimMechanics versions before Matlab R2012a. The latest generation is simpler modelling with a new library of blocks, with a much more powerful computing machine, more advanced visualization based on OpenGL $\AA$ computer graphics, and more detailed integration between SimscapeTM products. SimMechanics first and last generation technologies have different sets of capabilities. Furthermore, Matlab automatically builds the imitation model of the parallel robot and the simulation of its motion (Figure7).

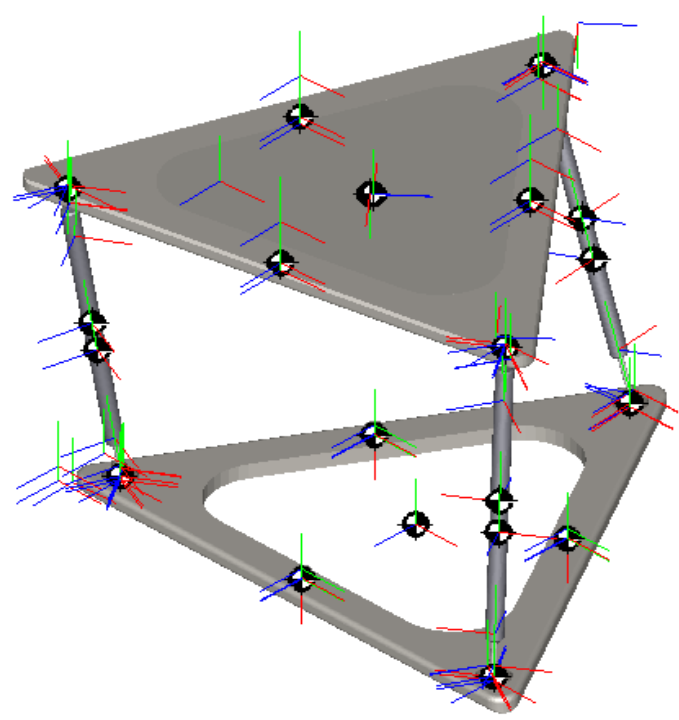

Fig. 7. Model simulation built in Matlab/Simulink

\section{PID CONTROL OF THE TRIPOD}

The Proportional Integral Derivative (PID) controlled law of motion management introduces a new, time-dependent variable, which is denoted by $\xi$ and whose time differential is:

$$
\dot{\xi}=\widetilde{q} .
$$

The previously defined law now receives the form:

$$
\tau=k_{p} \tilde{q}+k_{v} \dot{\tilde{q}}+k_{i} \xi
$$

By combining the previous equations, we define the behaviour of a manipulative robot with $n$ degrees of freedom during its management of the PID controller:

$$
B(q) \ddot{q}+C(q, \dot{q}) \dot{q}+g(q)=k_{p} \tilde{q}+k_{v} \dot{\tilde{q}}+k_{i} \xi
$$

or the solution for the equivalent in relation to the vector of the position is:

$$
\left[\xi^{T} 0^{T} 0^{T}\right]^{T} .
$$

To achieve the desired position $q_{d}$ for which $\xi^{*}$ is a constant, one way is to solve a differential equation where $\tau_{0}$ is a constant vector and the solution is given with:

$$
\xi^{*}=k_{i}^{-1} \tau_{0}
$$

If we assign a constant moment to the manipulation robot $\tau=\tau_{0}$, the solution to the previous equation is simply the position vector $q$ and the velocity $\dot{q}$. In case when the desired position $q_{d}$ is a function of the time, the equation has no solution, i.e. it can not be expected that the error of position $q$ is tending to 0 . In the best case also assuming that the initial error of the positions $q(0)$ and $\dot{q}(0)$ the velocity are small, so the error of positions $q$ over time remains limited. In this case, the PID controller is connected to the mobile platform, as shown in Figure 8.

The P, I, and D amplifiers can be modified by clicking in the according blocks. The PID controller manages the trajectory that describes the mobile platform, which is actually the ultimate goal of the parallel robot controllability. By changing the values of the proportional, differential and integral amplifier, its position, velocity and acceleration are changing. Namely, with the aid of a sensor, we can explicitly obtain the schedules of displacement, speed and acceleration corresponding to the given ratios for the amplifiers. To calculate these three sizes, we create subsystems with mathematical operations as shown in Figure 9

The subsystems contain blocks with which the displacement, velocity and acceleration vectors along the three axes are depicted in one graph as total displacement, total speed and total acceleration, using the well-known equation:

$$
\begin{aligned}
& p=\sqrt{p_{1}^{2}+p_{2}^{2}+p_{3}{ }^{2}}, \\
& v=\sqrt{{v_{1}}^{2}+v_{2}{ }^{2}+v_{3}{ }^{2}}, \\
& a=\sqrt{a_{1}^{2}+a_{2}{ }^{2}+{a_{3}}^{2}}
\end{aligned}
$$




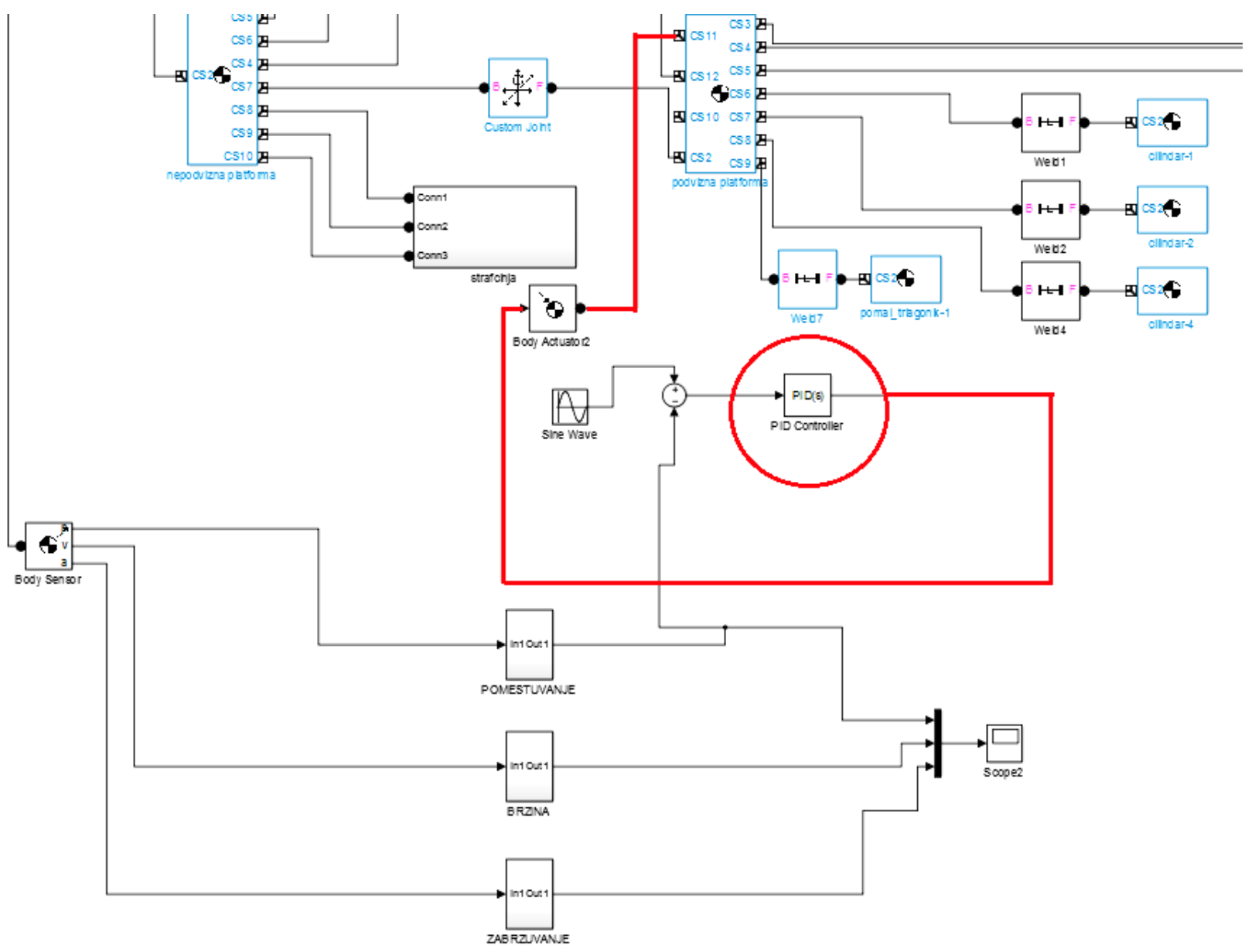

Fig. 8. Block diagram in Matlab/Simulink with PID control

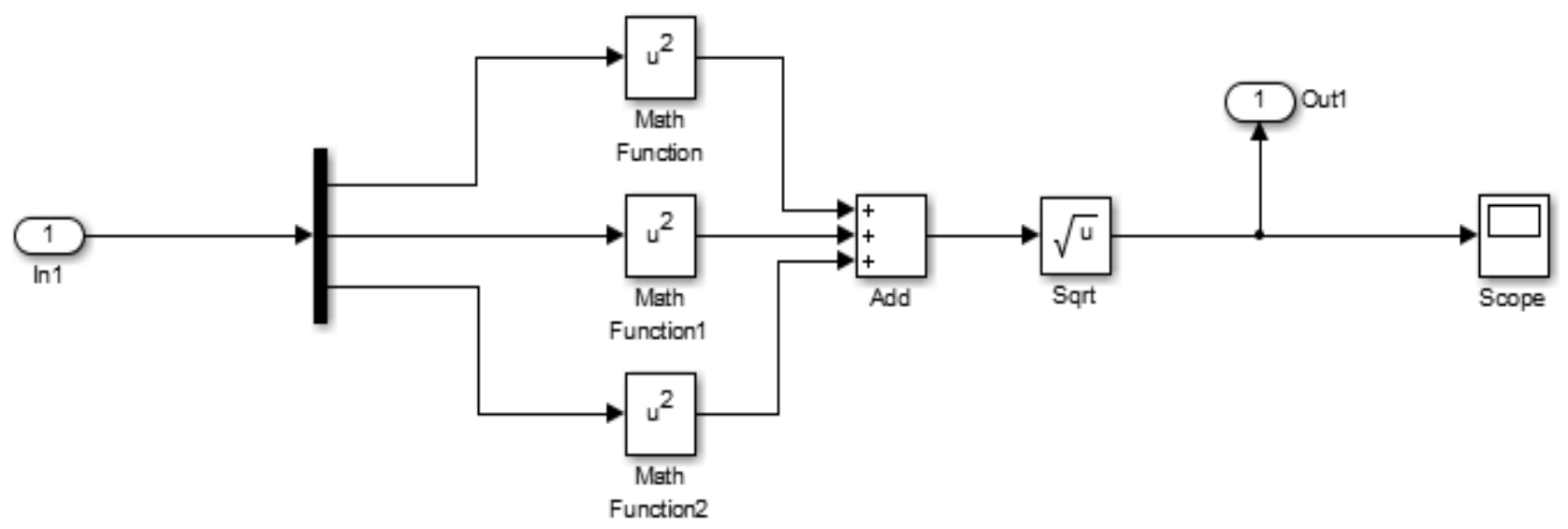

Fig. 9. Calculation of the position, velocity and acceleration

\section{RESULTS}

To show and verify the function of the subsystems, the values for the position, speed, and shift in the values of the amplifiers of the controller $P=$ $0.8, I=0.2$ and $D=0.2$ are selected arbitrarily. The mobility examination of the mobile platform is proceeded during a period of 3 seconds $(T=3)$. The graphs for the position, velocity and acceleration accordingly are given in Figure 10. These graphs were obtained for the chosen arbitrary values of the PID controllers amplifiers that we have set in advance. 
The graphs will be different for different amplifier values. This means that with the PID controller we directly influence on the movement of the centre of gravity of the mobile platform, that is, its trajectory, which was actually the purpose of its installation. We also control its speed and acceleration, thus affecting the dynamics of the manipulator.

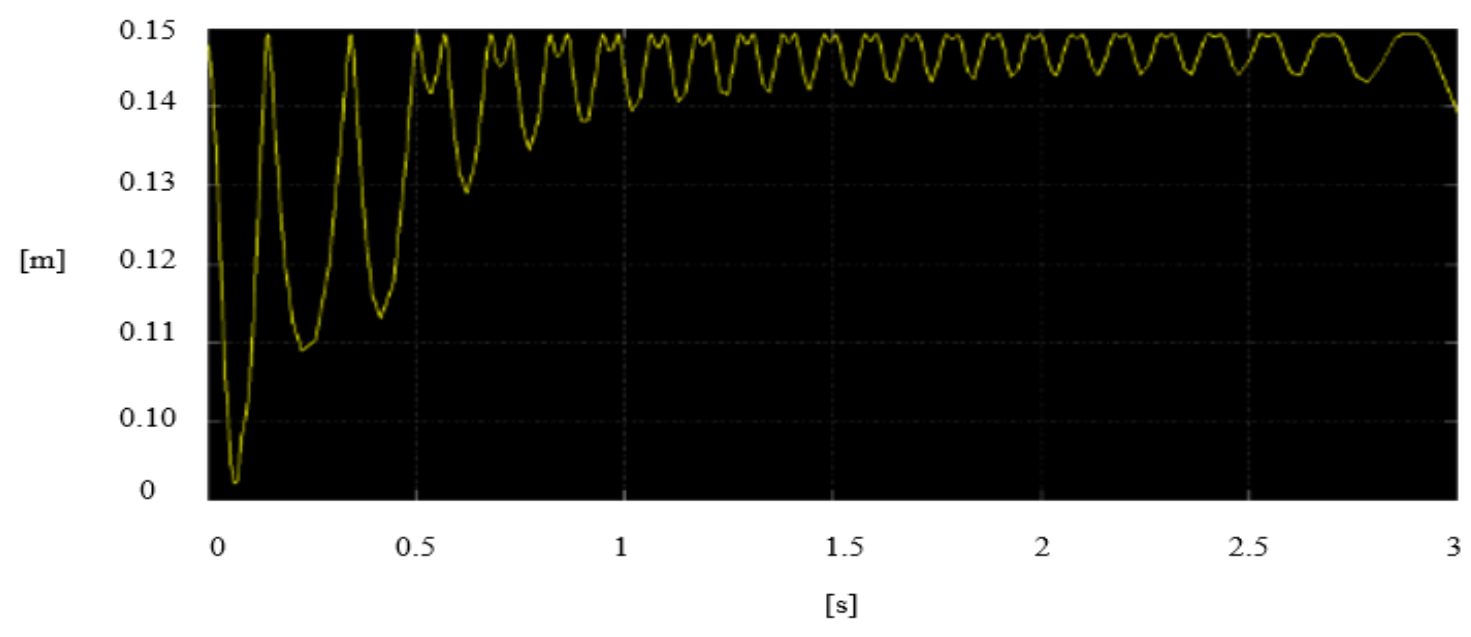

a)

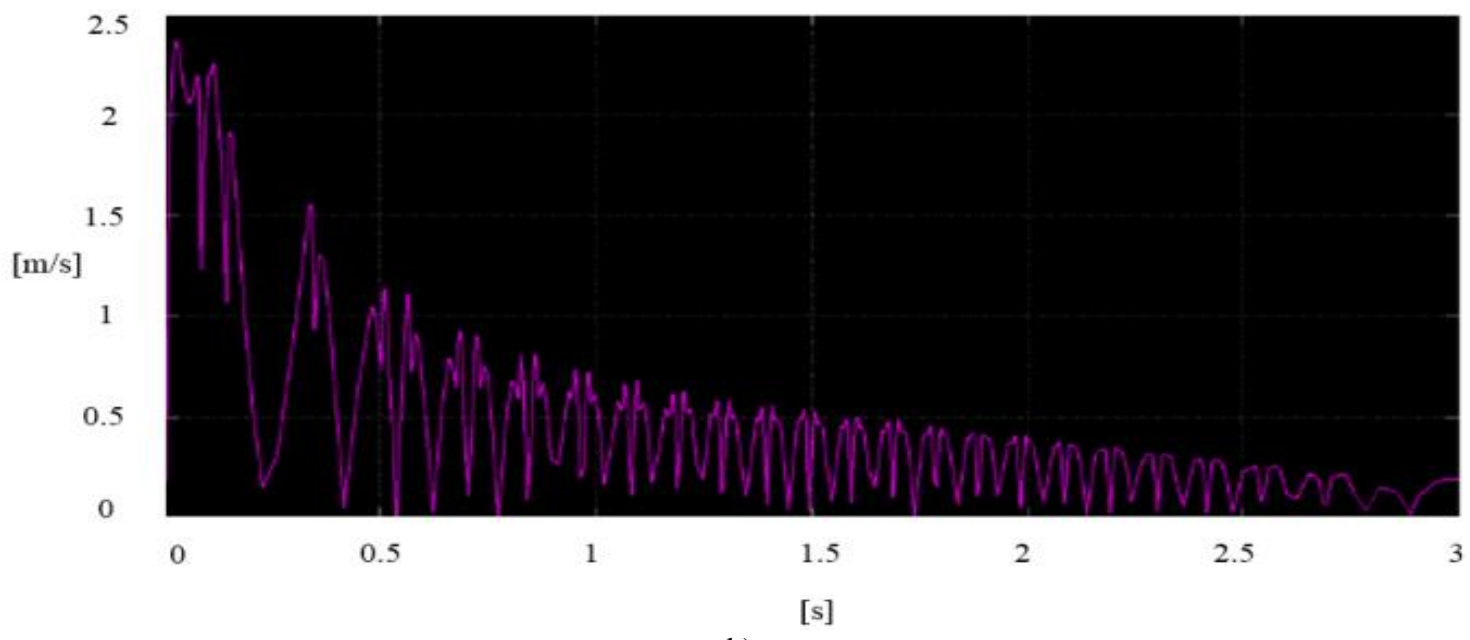

b)

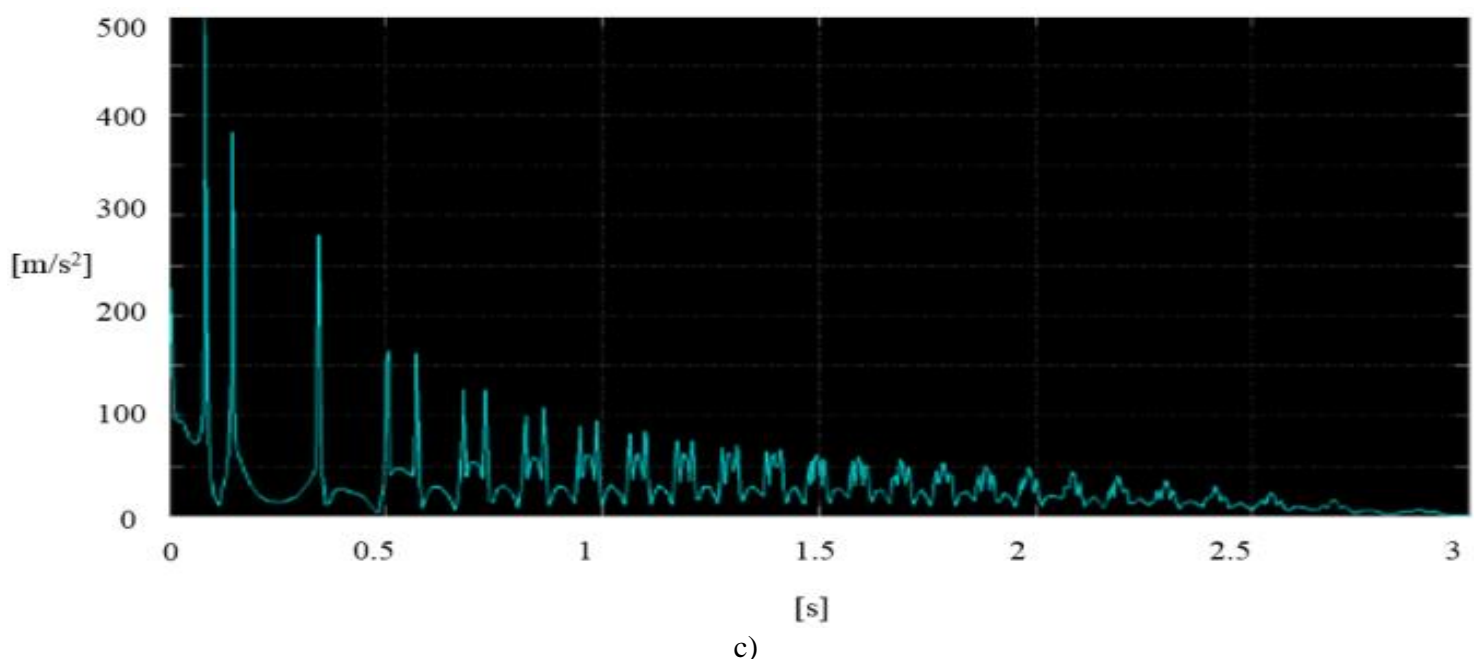

Fig. 10. Graphs for the a) position, b) velocity and c) acceleration 


\section{CONCLUSION}

With the help of the software package "Solid Works", a new parallel manipulator with three degrees of freedom was modelled. The structure of the manipulator consisted of three legs, each connected with a rotary pair to the movable and stationary platform of the manipulator. Direct and inverse kinematics was considered for this manipulator, following with simulation of the motion. Finally, the movement of the mobile platform was controlled by a PID controller, with reference to the reliability of the trajectory of the mobile platform from the values of the PID controllers.

Primarily, the purpose of this paper work was to look at parallel manipulators, whose applications today are innumerable and spread new horizons in the robotics industry. Furthermore, the possibilities of direct communication between the Solid Works and Matlab/Simulink software packages for modelling a parallel manipulator through the Multibody tool were presented. So far, the application of these two software packages as independent has perhaps been more complicated, but through the Multibody tool, it has become unlimited. The PID controller was considered as the most used in today's applications in the technology processes and was used as an ideal option for managing the parallel manipulator in order achieving complex trajectories which is widely used and extremely important.

\section{REFERENCES}

[1] Xi, F., Li, Y. and Wang, H.: Module-based method for design and analysis of reconfigurable parallel robots. Frontiers of Mechanical Engineering, 6 (2), pp. 151-159 (2011).

[2] Xi, F., Xu, Y., Xiong, G.: Design and analysis of a reconfigurable parallel robot. Mechanism and Machine Theory, 41 (2), pp. 191-211 (2006).

[3] Bi, Z. M., Lang, S. Y.: Kinematic and dynamic models of a tripod system with a passive leg. IEEE / ASME Transactions on Mechatronics, 11 (1), pp. 108-111 (2006).

[4] Karouia, M., Hervé, J. M.: A three-DOF tripod for generating spherical rotation. In: Advances in Robot Kinematics, Springer, Dordrecht, 2000 (pp. 395-402).

[5] Laski, P. A., Takosoglu, J. E., Blasiak, S.: Design of a 3DOF tripod electro-pneumatic parallel manipulator. Robotics and Autonomous Systems, 72, pp. 59-70 (2015).

[6] Staicu, S.: Recursive modelling in dynamics of Delta parallel robot. Robotica, 27 (2), pp. 199-207 (2009).

[7] Lapusan, C., Matis, V., Balan, R., Hancu, O., Stan, S. and Lates, R.: Rapid control prototyping using Matlab and dSpace. Application for a planar parallel robot. IEEE International Conference on Automation, Quality and Testing, Robotics,Vol. 2, pp. 361-364). IEEE, May 2008.

[8] Jovčevski, D., Djidrov, Marjan, Mickoski, H.: Kinematic model analysis of a parallel manipulator with six and three degrees of freedom, Mechanical Engineerring - Scientific Journal, Vol. 36, No. 2, pp. 137-144 (2018). ISSN $1857-$ 5293.

[9] Stan, S. D., Manic, M., Maties, V., Balan, R.: Kinematics analysis, design, and control of an Isoglide3 Parallel Robot (IG3PR). In: 34th Annual Conference of IEEE Industrial Electronics, IEEE, November 2008 (pp. 2636-2641), 